January 2010

\title{
Familial clustering of cancer in two tertiary care hospitals in Nairobi, Kenya
}

\author{
G. W. Kiarie \\ University of Nairobi \\ N. O. Abinya \\ Aga Khan University \\ M. D. Joshi \\ University of Nairobi \\ G. N. Lule \\ University of Nairobi \\ G. Z. Mutuma \\ Kenya Medical Research Institute
}

Follow this and additional works at: http://ecommons.aku.edu/eastafrica_fhs_mc_intern_med Part of the Other Medical Specialties Commons

\section{Recommended Citation}

Kiarie, G. W., Abinya, N. O., Joshi, M. D., Lule, G. N., Mutuma, G. Z. (2010). Familial clustering of cancer in two tertiary care hospitals in Nairobi, Kenya. East African Medical Journal, 87(1), 9-13.

Available at: http://ecommons.aku.edu/eastafrica_fhs_mc_intern_med/10 
East African Medical Journal Vol. 87 No. 1 January 2010

FAMILIAL CLUSTERING OF CANCER IN TWO TERTIARY CARE HOSPITALS IN NAIROBI, KENYA

G. W. Kiarie, MBChB, MMed (Nbi), Med. Onc. (Lond), Lecturer, Department of Clinical Medicine and Therapeutics, College of Health Sciences, University of Nairobi, P.O. Box 19676 - 00202, Nairobi, Kenya, N. O. Abinya, Associate Professor, Department of Medicine, Aga Khan University Hospital Nairobi, P.O. Box 30270 - 00100, Nairobi, Kenya, M. D. Joshi, MBChB, MPH, FACC, MMed, Senior Lecturer and Director, Clinical Epidemiology Unit, University of Nairobi, G. N. Lule, FRCP(E), MBChB, MMed (Nbi), Post Grad Dip. Inf (LSHTM), MSc Inf. (Lond), Professor, Department of Clinical Medicine and Therapeutics, College of Health Sciences, University of Nairobi, P.O. Box 19676 - 00202, Nairobi, Kenya, College of Health Sciences, University of Nairobi, P. O. Box 19676 - 00202, Nairobi, Kenya and G. Z. Mutuma, Forensic Pathologist and Senior Research Officer, Kenya Medical Research Institute, P. O. Box 54840, Nairobi, Kenya

Request for reprints to: Dr. G. W. Kiarie, Department of Clinical Medicine and Therapeutics, College of Health Sciences, University of Nairobi, P. O. Box 19676 - 00202, Nairobi, Kenya

\title{
FAMILIAL CLUSTERING OF CANCER IN TWO TERTIARY CARE HOSPITALS IN NAIROBI, KENYA
}

\author{
G. W. KIARIE, N. O. ABINYA, M. D. JOSHI, G. N. LULE and G. Z. MUTUMA
}

\begin{abstract}
Objective: To describe the occurrence of cancers in families of individuals diagnosed cancer.

Design: Cross-sectional descriptive study.

Setting: Outpatient cancer clinics at Kenyatta National Hospital (KNH) and Radiotherapy

Clinic at Nairobi Hospital.

Subjects: Patients with a tissue histological or cytological diagnosis of cancer.

Main outcome measures: A reported family history of cancer.

Results: A total number of 485 cancer patients were recruited, 382, from KNH and 103

from Nairobi Hospital. These index cases had 45 different types of cancer, with the most common being breast and uterine-cervical malignancies. Prevalence of family history of cancer was found to be $\mathbf{1 8 . 8} \%$ and was highest among $1^{\text {st }}$ degree relatives. Documentary evidence was seen in $48.4 \%$ and history of cancer corroborated by medical personnel in an additional $11 \%$. In $18.7 \%$ of cases more than one relative was interviewed to confirm the family history of cancer. Educational levels of the index cases correlated with knowledge of family history of cancer, with those of higher educational level having been more informed about their families' medical history. There was a prevalence of familial cancers of $30 \%$ at Nairobi Hospital patients and $15.7 \%$ at $\mathrm{KNH}$ patients.

Conclusion: We found the prevalence of family history of cancer in our population to be $18.8 \%$ and was highest among $1^{\text {st }}$ degree relatives. This has implications for targeted screening and therefore early diagnosis which is beneficial.
\end{abstract}

\section{INTRODUCTION}

Cancer is a major cause of morbidity and mortality in developed countries and of increasing concern in developing countries. Its treatment is often costly and associated with high mortality, whereas screening and early diagnosis is life saving.

Epidemiological surveys indicate that patients with certain cancers often have a family history of cancer (1). Familial cancers with clear patterns of mendelian inheritance are very rare. However in the past decade many genes responsible for these rare disorders have been identified (1).

The cancer genes characterised and known inheritance patterns are associated with specific cancer syndromes comprising two or more malignancies in "cancer families". Targeted genetic testing and screening of susceptible individuals is being carried out in developed countries. For example it has been found that screening and genetic testing (for BRCA 1 and 2 genetic markers) reduces breast cancer mortality and has important implications in the natural history of the disease. Evidence suggests that metastases occur very early in breast cancer and it should be considered a systemic disease from the onset due to delay in diagnosis of majority of cases. Studies show that targeted surveillance, therefore earlier screening of women with a family history of breast cancer leads to improved survival (2). Breast cancer is the most common malignancy in women in Kenya making up $23.3 \%$ of women cancers (3). In the Kenyan woman, it occurs more in premenopausal ages, is a more aggressive disease presenting with metastases in $88 \%$ of the cases, with higher grades but similar histological types to white women (4). There is lower postitivity both endochrine receptors and Her/neu 2 
receptors (5), which correlates with poorer prognosis. African American women have similar poor prognostic indicators and a 37\% higher mortality than white women, in whom early referral and treatment is aimed at (6). In our setup high risk individuals from "cancer families" can undergo targeted screening that can be cost effective and life saving.

\section{MATERIALS AND METHODS}

Cases were recruited from $\mathrm{KNH}$ medical, surgical and radiotherapy outpatient clinics and Nairobi Hospital's radiotherapy unit. Most cancer patients seen at $\mathrm{KNH}$ were outpatients due to the hospital policy of limiting admission of chronic patients. KNHinpatients werenot included because of logistics of covering all the wards, difficulty in consecutive sampling of inpatients and potentialfor selection bias. TheKNHradiotherapyclinic operates as outpatient oncology follow-up clinic.

Inclusion and exclusion criteria: Patients with a documented diagnosis of cancer who consented to participation in the study were recruited. Secondary malignancies, such as HIV and post-transplant associated cancers were excluded.

Two research assistants assisted in screening the daily clinic attendance files for histological report of cancer. These patients were approached using a standardised information sheet. A written informed consent was obtained.

The principal investigator administered a standardised questionnaire to all the index cases and accompanying relatives. If no relative had accompanied the patient, their relatives were contacted and interviewed. A follow-up was made to interview other relatives who corroborated the presence or absence of a family history of cancer. Contact telephone numbers and addresses of relatives to be interviewed were provided by the index cases.

Cancer type and demographic details of theindex case were documented. Family history of cancer in patient's first and second degree relative was sought. A detailed family medical history of these relatives was taken. An "important-other" family member, based on educational level, prominence and influence in the family and a willingness to cooperate with the investigator, was identified and interviewed in person, via telephone or mail, seeking to confirm the family history as reported by index case and accompanying relatives. Cancer type, institution where diagnosis was made, attending physician, year of diagnosis, follow-up clinic as well as demographics of the other relative with cancer were noted. This helped in accessing documentary evidence of the same. If alive the relative with cancer was interviewed in person or via telephone contact.

Documentary evidence of the relatives' with cancer was also sought from the existing cancer registries in $\mathrm{KNH}$ and KEMRl (Kenya Medical Research Institute), other hospital records, death certificates, pathology reports and verbal corroboration from attending physicians were sought. Consequently the level of evidence, of a family history of cancer was categorised on basis of level of cross validation as follows:

Confirmed:Documentary evidence obtained, such as hospital discharge summaries, record cards, DXT cards ,histology reports, prescriptions and perusal of attending physicians' notes.

Highly probable: Verbal confirmation of history by relatives whowere medical for example doctors, clinical officers or nurses, as well attending physicians.

Probable: Verbal corroboration from patient and two other relatives including the "important-other relative".

Least probable: Verbal confirmation from patient and any other relative.

\section{RESULTS}

Five hundred and thirteen cases were screened and 485 were recruited during the period of June to November 2003; $78.8 \%$ of sample from $\mathrm{KNH}$, and $21.2 \%$ from Nairobi Hospital. Male to female ratio was 1:1.5 and age ranged from 13 to 93 years, with $44 \%$ in the 31 to 50 years age group and $16.7 \%$ in 60 to 80 years. Sixty eight per cent drawn from rural and $32 \%$ from urban areas. They were mainly from Central province, followed by Nyanza, Eastern and Coast provinces. This follows the referral patterns of outpatients attending clinics in KNH. The ethnicity of index cases also follows the catchments area of the two hospitals implying unbiased sampling.

Educational levels of the index cases were: $17.3 \%$ no formal education, $37.7 \%$ primary, $28.7 \%$ secondary and $16.3 \%$ tertiary level. The Nairobi Hospital cohort had higher levels of formal education while $64 \%$ of $\mathrm{KNH}$ cohort had primary level education or had received no formal education at all.

Index cases had 45 different cancer types, with the most frequent being breast $(13.8 \%)$ and uterine cervix (14\%). Post-nasal tumour $(11 \%)$, skin cancers $(6.9 \%)$, non PNS head and neck tumours $(6 \%)$ and laryngeal cancers $5 \%$.

A prevalence of family history of cancer was established in 18.8\% (95\% C.I $1522 \%$ ). Prevalence of positive family history was $12.4 \%$ among $1^{\text {st }}$ degree relatives and $6.4 \%$ in $2^{\text {nd }}$ degree relatives. Some families had a multiple family history of cancer; $25 \%$ had more than one relative with cancer, two cases had four relatives each with cancer. A total of 125 relatives had cancer from 91 index cases

Familyhistory of cancer was validated as confirmed or highly probably in $59.4 \%$ of cases (Table 1). On stratifying according to hospital and educational level of index cases, a higher prevalence of positive family 
history was found among those of higher educational attainment and among the Nairobi Hospital cohort $(30 \%$; 95\% CI 0.55 .20$)$, in contrast to the prevalence in the $\mathrm{KNH}$ cohort ( $5.7 \%$ (CI 0.54-.20) (Table 2).

\section{Table 1}

Prevalence of a family history of cancer according to institution and education level

\begin{tabular}{lcccc}
\hline $\begin{array}{l}\text { Hospitals/KNH } \\
\begin{array}{l}\text { Education } \\
\text { Level }\end{array}\end{array}$ & $\begin{array}{c}\text { KNH FHx } \\
\text { of } \\
\text { cancer }\end{array}$ & $\begin{array}{c}\text { NRB } \\
\text { Hosp }\end{array}$ & $\begin{array}{c}\text { NRB } \\
\text { FHX of } \\
\text { cancer }\end{array}$ \\
\hline None & 70 & 6 & 14 & 2 \\
Primary & 176 & 7 & 7 & 5 \\
Secondary & 107 & 24 & 32 & 8 \\
Tertiary & 29 & 23 & 50 & 16 \\
\hline Total & 382 & $60(15.7 \%)$ & 103 & $31(30 \%)$ \\
\hline
\end{tabular}

Approximately $16.8 \%$ of relatives were living, half of whom were interviewed, while $83.2 \%$ were dead. Relatives with cancer had an age distribution skewed to the right and majority were aged over 60 years (Figure 1) and of male gender (54\%).

There were $61 \%$ first degree relatives and 39\% second degree relatives among the relatives with cancer. Of the 66 breast cancer index cases $36 \%$ had a family history of cancer; $66 \%$ were first degree relatives and $34 \%$ were second degree relatives. There were 67 index cases with cancer of cervix, of these $21 \%$ had a family history of cancer and $43 \%$ were first degree relatives and $58.2 \%$ second degree relatives. There were 125 relatives with 24 different cancers, the most common being cancers of uterine cervix and breast; a frequency pattern similar to that of index cases (Figure 2).

Table 2

Differences in familial clustering in the breast cancer and uterine cervix cancer

\begin{tabular}{lllll}
\hline Cancer type & $\begin{array}{l}\text { Cancer of } \\
\text { breast }\end{array}$ & $\begin{array}{l}\text { Cancer of } \\
\text { cervix }\end{array}$ & Cancer PNS & Total \\
\hline Family HX of CA & $24(36 \%)$ & $14(21 \%)$ & $7(13 \%)$ & 45 \\
No Family HX of CA & 42 & 53 & 46 & 141 \\
\hline Total & 66 & 67 & 53 & 186 \\
\hline
\end{tabular}

Chi - Square Calculation:

Degrees of freedom 2

Chi - square $=9.21511699921617$

$\mathrm{X}^{2}=9.2 \mathrm{P}<0.01$

This distribution is significant

Figure 1

Age distribution of relatives with cancer

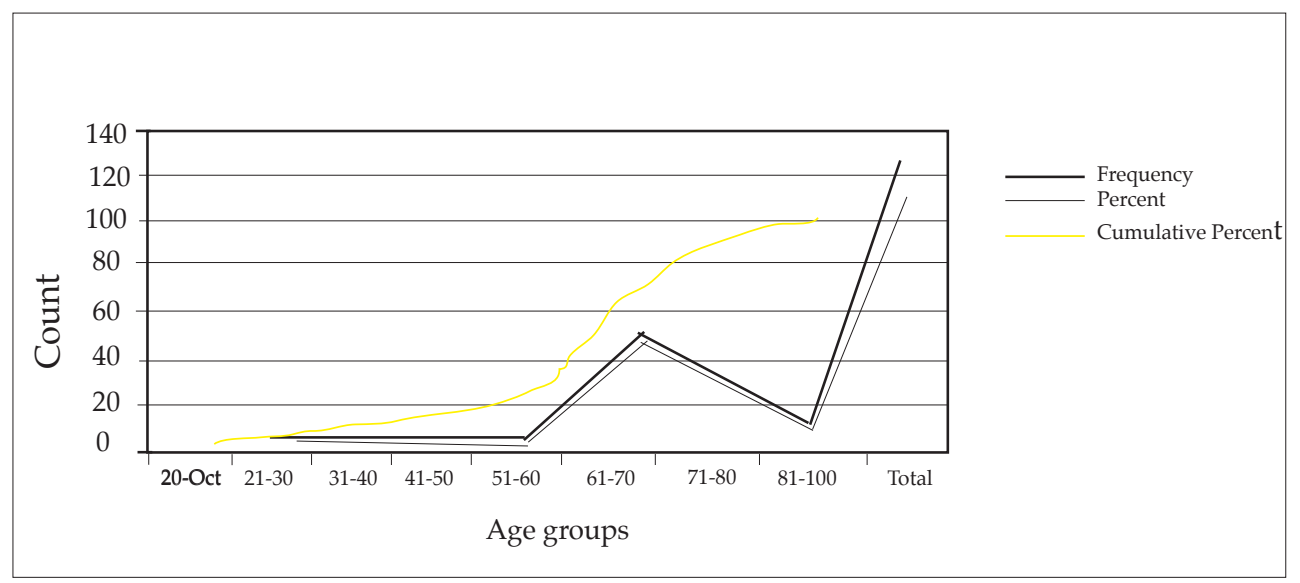


Figure 2

The common cancer types among relatives of index cases

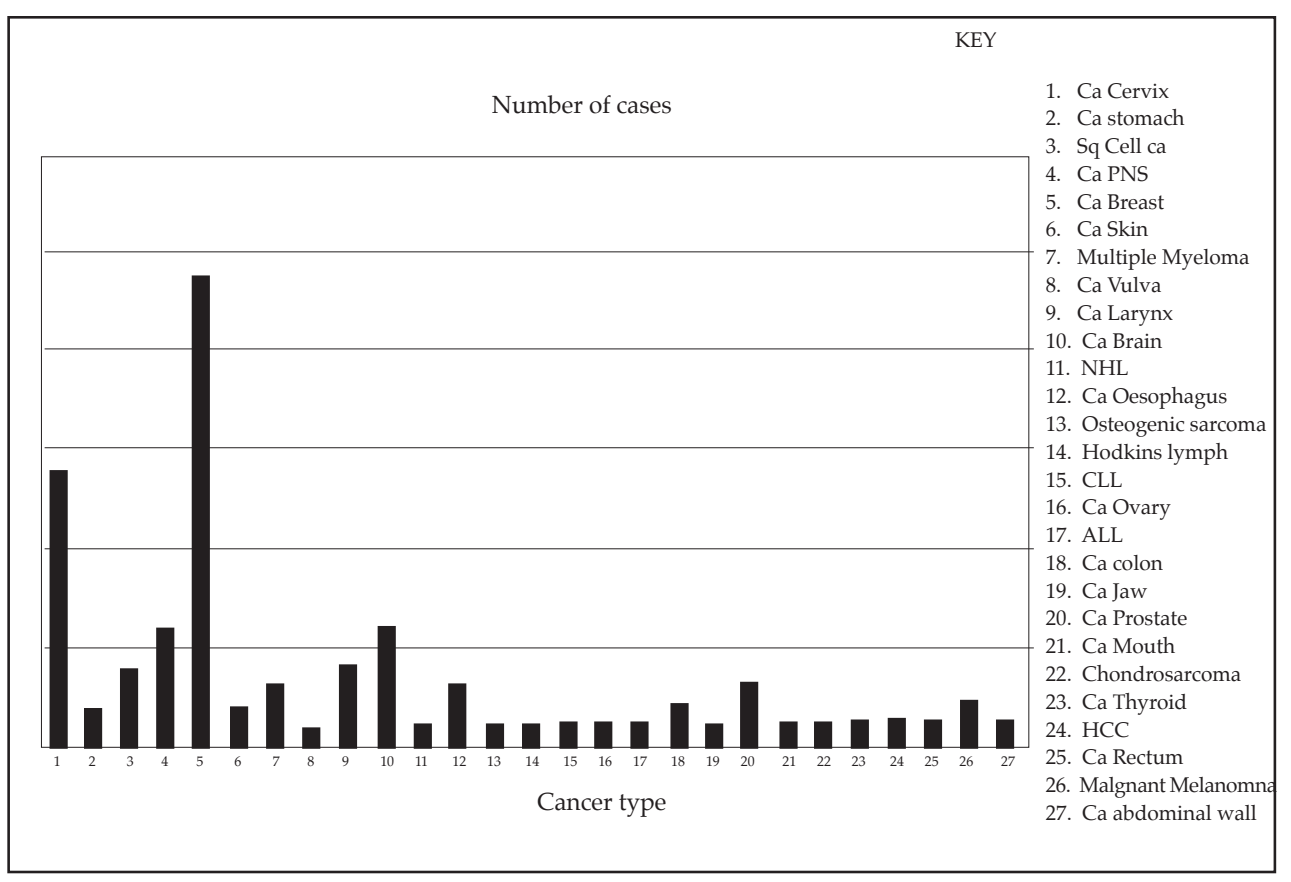

\section{DISCUSSION}

We found a prevalence of familial clustering of cancer of $18.8 \%$ (95\% C.I $15-22 \%$ ). This is the first such data in this region, as no data is available for sub-Saharan Africa but our data correlated with Western data in several areas. The general population risk for various malignancies ranges from $5-25 \%(7,8)$. In Utah and California combined data on 44,788 pairs of twins showed increased familial risk among twins of patients with stomach, colorectal, lung, prostate and breast malignancies (9). We found a familial clustering of $36 \%$ in breast cancer patients, while a Stockholm study showed $35 \%$ in breast cancer as well, with a younger age of onset in the familial group (10). All these studies used cancer registry data in contrast to recall as utilised in our study. Our finding may be an underestimate due to the various biases limiting verification of the family history of cancer. Recall bias was a major shortcoming of this study. Under reporting on account of illiteracy, lack of inter-family communication, geographical constraints, stigma of the disease and confidentiality issues can be expected to have biased our finding to the null. Poor record keeping and lack of updated cancer registries, limited verification of the information obtained. Over estimating on account of misclassification bias was minimised by verification of information at various levels. Limiting the analysis to verified confirmed family history of cancer gave a prevalence's similar to those in studies in which cancer registries were utilised.
Survival bias limited recruitment of cancer types that are rapidly fatal, as depicted by only three cases of hepatocellular cancer yet it is among the top five malignancies in our country.

Our findings are generalisable to the Kenya cancer population; firstly because our sample was unbiased, as is evident from the similar national cancer frequencies (11) and demographics of the index cases to those of other chronic disease patients attending outpatient clinics at the KNH (12). Secondly, $\mathrm{KNH}$ is the only national cancer referral treatment centre and third, the general population lack of awareness about possible familial clustering of cancer is not expected to have contributed significantly to a referral bias. As reported in European studies, we documented a higher prevalence in first degree as apposed to second degree relatives, and we view this as further validation evidence(13). In somestudies monozygotic twins have higher cancer risk than dizygotic twins of cancer patients (14).

Uterine cervical cancer in our sample did nothave a strong familial predilection as has been similarly reported in epidemiological data from the US and Europe with the occurrence being predicted more by environmental factors such as number of sexual partners, age at first intercourse and HPV infection (15). Investigators reporting clustering of cervical cancer in families have argued that these individuals shared the same environment and have common lifestyle patterns hence tendency to be infected with HPV (16). 
Whereas cancer is generally a disease of the elderly population, due to increased susceptibility as duration of exposure to carcinogens increases, the relatively younger age distribution in our study is a reflection of higher frequency of early occurring female gender cancers. In Western literature the common associations of parity, early age of delivery were not protective against ovarian cancer in those with a strong family history of cancer (17).

In conclusion we found a prevalence of familial clustering of cancer sin our setup to be approximately $18.8 \%$ and is highest amongst first-degree relatives at $12 \%$ compared to $6 \%$ for second-degree relatives. Breast cancer had a familial clustering prevalence of $36 \%$ and a same cancer concordance rate of $54 \%$. Multiple family history of cancer was highest in breast cancer cases. If an early diagnosis of cancers is made, many lives can be saved and cost of treatment reduced. An awareness of familial risk of cancer is important towards this end. Targeted screening of these family members will aid in early diagnosis and therefore reduce morbidity and mortality of the two most common malignancies in our environment.

\section{REFERENCES}

1. Anne, H. et al. Inherited Susceptibility to Cancer: clinical, predictive and ethical perspectives: $N$. Eng. J. Med. 1999; 340: 1125-1126.

2. Maurice, A., Evans, D. G., Shenton, A., et al. Screening younger women with family history of cancer - does early detection improve outcome? Eur. J. Cancer. 2006; 42:1385-1390.

3. Nairobi Cancer Registry: Cancer Incidence Report Nairobi 2000 -2002 KEMRl publication 2006.

4. Bjerregaard, B. and Kung'u, A. Breast cancer in Kenya: a histopathologic and epidemiologic study. East Afr. Med. J. 1992; 69: 22-26.

5. Abinya, et al, Experience of a single oncology clinic in Kenya. Asco. Proceedings. 2006.

6. Smigal, C., Jamal, A., Ward, E. et al. Trends in breast cancer by race and ethnicity: update 2006. CA Cancer J. Clin. 2006; 56: 168-183.
7. Rockhill, B., Weinberg, C.R. and Newman, B. Population attributable fraction estimation for established breast cancer risk factors: considering the issues of high prevalence and unmodifiability. Am. J. Epidemiol. 1998; 147: 826-833.

8. Mitchell, R.J. Campbell, H. Farrington S. M. et al. Prevalence of family history of colorectal cancer in the general population. Br. J. Surg. 2005; 92: 1161-1164.

9. Lichtenstein, P., Holm, N.V., Verkasal, P. K. and Iliadon, A. Enviromental and heritable factors in causation of cancer - analyses of cohorts of twins from Sweden, Denmark and Finland. N. Eng. J. Med. 2000; 343:78-85.

10. Margolin, S., Johansson, H., Rutqvist, L. E. et al. Family history, and impact on clinical presentation and prognosis, a population-based breast cancer cohort from the Stockholm count. Fam. Cancer. 2006; 5: 309 - 321 .

11. Cancer Registry Kenya Medical Research Institute (KEMRl).

12. Kenyatta National Hospital Clinic Regisry.

13. Negri, E. Braga, C. La Vecchia, Franceschi, C.S. and Parterzzini, F. Family history of cancer and risk of breast cancer. Int. J. Cancer. 1997; 72: 735-738.

14. Ahbolm, A., Lichtenstein, A. P., Malmstrom, H., et al . Cancer in twins: genetic and nongenetic risk factors. J. Nat. Cancer L. 1997; 287-293.

15. Slattery, M.L., Overall, J.C. Jr., Abbott, T. M. et al. Sexual activity, contraception, genital infections, and clerical cancer; support for a sexually transmitted disease hypothesis. Am. J. Epidemiol. 1989; 130: 248 $-258$.

16. Mc Dougall, J. K., Krum, C.P., Fenoglio, C.M. et al. Herpes virus - specific RNA and protein in carcinoma of uterine cervix. Proc. Natl. Acad. Sci. USA. 1982; 79: $3853-3857$.

17. Kerger, R. A. and Slattery, M. L. The impact of family history on ovarian cancer risk: The Utah population data base. Arch. Intern. Med. 1994; 139: 654-661. 